\title{
Effect of urea formaldehyde viscosity on urea formaldehyde and urea proparaldehyde copolymer composite
}

\author{
S. A. OSEMEAHON ${ }^{*}$, J. T. BARMINAS, B. A. ALIYU and F. Y. FAI \\ Department of Chemistry, Federal University of Technology, Yola, Nigeria. \\ "Corresponding author, Email: sundayosemeahon@yahoo.com
}

\begin{abstract}
This work investigates the effect of urea formaldehyde (UF) viscosity on a composite derived from copolymerization reaction between urea formaldehyde (UF) and urea proparaldehyde (UP). Some physical properties of the urea formaldehyde/urea proparaldehyde (UF/UP) copolymer obtained at different UF viscosities (3.91-207.08 mPa.s) were evaluated. The melting point, refractive index, density and formaldehyde emission were found to increase with increase in UF viscosity while the dry time, moisture uptake and elongation at break were found to decrease with increase in viscosity. UF viscosity below $10.82 \mathrm{mPa}$.s was found to produce UF/UP copolymer composite which is ductile and soluble in water. Beyond this value, the composite became insoluble in water. Thus processing of UF/PU copolymer resin for emulsion paint formulation should be carried out below $10.82 \mathrm{mPa}$.s viscosity level. The results obtained from this experiment will offer formulators different options and will help to control formulation processes towards developing UF/UP copolymer composite as a paint binder for emulsion paint formulation.

(c) 2008 International Formulae Group. All rights reserved.
\end{abstract}

Keywords: Copolymerization, viscosity, Paint binder.

\section{INTRODUCTION}

The coating industry, as with most industries today, is continually being challenged by many influencing drivers to change, and satisfy the continually evolving environment in which we live. Probably the most critical challenge for the industry has been the need to meet environmental regulations especially as it affects the emission of volatile organic solvents (VOC) from coating surfaces. The need to reduce VOC from our environment can be considered a survival need as this will help to reduce the problems of depletion of ozone layer in the atmosphere largely responsible for global climatic change.

With the advert of the regulations on air pollution, and for safety consideration, there have been continued interests in the search for alternative raw materials and new formulations to reduce the overall volatile organic compounds in surface coatings (Gan and Tan, 2001). Recently, much research has focused on replacing solvent-based paints with water based paints (Mohammed et al., 2001; Li et al., 2001). The advantages of water borne paint include being nonpolluting, easy to handle, quick drying, economic and environmentally friendly. However, although most household paints are water-based, this is not true of industrial paints. Because of the special requirements of the industrial coatings, satisfactory water-based polymers with the required properties have not yet been developed (Gooch, 1997). Therefore a significant challenge in this drive to reduce VOC is the need for the water-borne technology to deliver the enamel type properties characteristic of solvent-born coatings. 
The acceptance of urea formaldehyde resin as a universal material in many engineering areas such as in the coating industry is impeded by some of its inherent qualities such as brittleness, poor water resistance and formaldehyde emission (Barminas and Osemeahon, 2006; Osemeahon and Barminas, 2007). These disadvantages limit its uses. However, UF resins offer a wide range of conditions that make synthesis of these resins with important properties such as gel time, tack and spreading ability of the uncured resin possible. Also, formaldehyde emissions and the durability of the cured resin can be controlled and specifically tailored for the final use of the resins (Osemeahon and Barminas, 2006b).

Park et al. (2002) reported that the ultimate performance of a fully cured amino resin largely depends on its synthesizing parameters, including the ingredient mole ratio, catalyst, viscosity, reactivity and so on. These parameters are frequently adjusted empirically to tailor the resin properties to specific production requirements such as the resin reactivity, formaldehyde emissions, water resistance etc.

In the coating industry an understanding of the viscosity of the paint binder is very important because it controls factors such as flow rates, leveling and sagging, thermal and mechanical properties, dry rate of paint film and adhesion of the coating to substrate. Kim (2001) and Osemeahon and Barminas (2007) reported that the polymerization reaction in urea formaldehyde resin synthesis is normally ended when the viscosity of the reaction mixture obtain the established optimal. Thus in the coating industry a knowledge of the viscosity of the binder is of considerable importance both from the manufacturing processes, pot stability and rate of cure of the paint film (Achi, 2003).

In our previous experiments (Barminas and Osemeahon, 2007; Osemeahon et al., 2007), we reported both the synthesis of UF through a new synthetic route and the successful copolymerization of urea formaldehyde with urea proparaldehyde (UP) with this new class of UF resin as a way of developing a paint binder for emulsion paint formulation from amino resin. In order to optimize the copolymerization reaction between UF and UP, this experiment is set out to investigate the effect of UF viscosity on the UF/UP copolymer composite. This will offer formulators with varied options to tailor quality performance.

\section{MATERIALS AND METHODS Materials}

Urea, formaldehyde, proparaldehyde, sodium dihydrogen phosphate, sulphuric acid, sodium hydroxide pellets and sucrose were reagent grade products from the British Drug House (BDH). All materials were used as received.

\section{Resin Synthesis}

Trimethylol urea was prepared by the method described by Barminas and Osemeahon, (2006). One mole (6.0 g) of urea was reacted with three moles $(24.3 \mathrm{ml})$ of $37 \%(\mathrm{w} / \mathrm{v})$ formaldehyde using $0.2 \mathrm{~g}$ of sodium dihydrogen phosphate as catalyst. The $\mathrm{pH}$ of the solution was adjusted to 6 by using $0.5 \mathrm{M} \mathrm{H}_{2} \mathrm{SO}_{4}$ and $1 . \mathrm{O} \mathrm{M} \mathrm{NaOH}$ solutions. The solution was then heated in a thermostatically controlled water bath at $70{ }^{\circ} \mathrm{C}$. The reaction was allowed to proceed for $2 \mathrm{~h}$ after which the sample was removed and kept at room temperature $\left(30{ }^{\circ} \mathrm{C}\right)$.

Propylol urea, was synthesized by reacting one mole $(6.0 \mathrm{~g})$ of urea with one mole $(7.4 \mathrm{ml})$ of $97 \%(\mathrm{w} / \mathrm{v})$ proparaldehyde at $\mathrm{pH}$ of 8 (Osemeahon and Barminas, 2007) to produce monopropylol urea. Other procedures followed same as described above. Copolymerization of MU with PU was carried out by reacting $50 \mathrm{ml}$ of UF with $50 \mathrm{ml}$ of UP solutions at $30{ }^{\circ} \mathrm{C}$. The solutions were allowed to stay for $24 \mathrm{~h}$ before the commencement of the various tests. The UF samples with different viscosities used in this experiment were obtained by removing $60 \mathrm{ml}$ of resin from the synthesized UF resin at $24 \mathrm{~h}$ intervals for the period of $168 \mathrm{~h}$ and their viscosities determined (Osemeahon et al., 2007),

\section{Preparation of UF/UP Composite Films}

Copolymer composite film of UF and UP film was obtained as reported earlier (Osemeahon and Barminas, 2007). In brief, 50 $\mathrm{ml}$ of UF was added to $50 \mathrm{ml}$ of UP to form UF/UP copolymer composite. The mixture was stirred and left for $24 \mathrm{~h}$ at room 
temperature $\left(30{ }^{\circ} \mathrm{C}\right)$ and then poured into a glass petri dish for casting. The composite was also allowed to cure and set for seven days at $\left(30{ }^{\circ} \mathrm{C}\right)$. The above procedure was repeated at different UF viscosities (3.91$207.08 \mathrm{mPa} . \mathrm{s})$. The physical properties of these films were then investigated.

\section{Determination of Viscosity}

The method reported by Barminas and Osemeahon (2007) was adopted for the determination of the viscosity of UF resin. In brief, a $100 \mathrm{ml}$ Phywe made graduated glass macro-syringe was utilized for the measurement. The apparatus was standardized with $20 \%$ (W/V) sucrose solution whose viscosity is $2.0 \mathrm{mPa}$.s at $30{ }^{\circ} \mathrm{C}$. The viscosity of the resin was evaluated in relation to that of the standard sucrose solution at $30{ }^{\circ} \mathrm{C}$. Five different readings were taken for each sample and the average value calculated.

Determination of Density, Turbidity, Melting point and Refractive Index

The above properties were determined according to standard methods (AOAC, 2000). The density of the different resins was determined by taking the weight of a known volume of resin inside a density bottle using metler (Model, AT400) weighing balance. Five readings were taken for each sample and average value calculated. The turbidity of the resin samples was determined by using Hanna microprocessor turbidity meter (Model, H193703) (Barminas and Osemeahon, 2006). The melting points of the different film samples were determined by using Galenkamp melting apparatus (Model, MFB600-010F). The refractive indices of the resin samples were determined with Abbe refractometer (Barminas and Osemeahon, 2006).

\section{Determination of Moisture Uptake}

The moisture uptakes of the different resin film were determined gravimetrically (Osemeahon and Barminas, 2007). Known weight of the sample was introduced into a desiccator containing a saturated solution of sodium chloride. The increase in weight (wet weight) of the sample was monitored until a constant weight was obtained. The differences between the wet weight and dry weight of each sample were then recorded as the moisture intake by resin. Triplicate determinations were made for each sample and the average value recorded.

\section{Determination of Formaldehyde Emission}

Formaldehyde emission test was performed by using the standard $2 \mathrm{~h}$ desiccator test as earlier reported (Osemeahon and Barminas, 2007). . The mold used was made from aluminium foil with a dimension of $69.6 \mathrm{~mm} \times 126.5 \mathrm{~mm}$ and thickness of 12.0 $\mathrm{mm}$. The emitted formaldehyde was absorbed in $25.0 \mathrm{ml}$ water and analyzed by a refractometric technique using Abbe refractometer. Triplicate samples were used and average value taken.

\section{Tensile Test}

Tensile properties (tensile strength and elongation at break) were measured as described by Osemeahon et al. (2007), using Instron Testing Machine (Model 1026). Resin films of demension $50 \mathrm{~mm}$ long, $10 \mathrm{~mm}$ wide and $0.15 \mathrm{~mm}$ thick were brought to rapture at a clamp rate of $20 \mathrm{~mm} / \mathrm{min}$ and a full load of $20 \mathrm{~kg}$. Five runs were done for each sample and the average elongation evaluated and expressed as the percentage increase in length.

\section{Dry Time and Water Solubility}

The relative degree of cure (Reaction time) was expressed in the form of dry time (dry to touch). This was measured by the qualitative finger-making test (Ali et al., 2001). The solubility of methylol urea in water was obtained by mixing $1 \mathrm{ml}$ of the resin with $5 \mathrm{ml}$ of distilled water at room temperature $\left(30 \quad{ }^{\circ} \mathrm{C}\right)$ (Osemeahon and Barminas, 2006).

\section{RESULTS AND DISCUSSION Dry time}

One of the short comings of urea formaldehyde and urea proparaldehyde copolymer composite is that the dry time is relatively too high when compared to the traditional paint binders (Osemeahon and Barminas, 2007). The time it takes for a paint to dry (reaction time) after application is an important factor for the paint formulator (Osemeahon et al., 2007). This is because if the paint dries too fast, it will be prone to brittleness and if it dries too slowly, the paint may be subjected to pick up dirt (Trumbo et al., 2001). Figure 1 shows the effect of UF 
viscosity on the dry time of UF/UP copolymer composite. The result shows that the dry time decreases with increase in UF viscosity in the copolymer. This is attributed to increase in molecular weight and cross link density with increase in UF viscosity (Osemeahon and Barminas, 2006a).Thus a UF/UP copolymer resin with high rate of drying may be obtained at high viscosity of UF resin.

\section{Refractive index}

Gloss is an important factor of many coating products (Osemeahon et al., 2007). The gloss of a paint coating with or without pigments is a function of the refractive index of the surface, the angle of incidence of the beam of light and the nature of the material (Trezza and Krochta, 2001).

Figure 2 shows the effect of UF viscosity on the refractive index of UF/UP copolymer composite. It is observed that the refractive index of the UF/UP copolymer increases rapidly from 3.91-10.82 mPa.s viscosity levels. After this, little or no change in refractive index is observed with further increase in UF viscosity. This is attributed to the differences in molecular weigth and cross link density of the different viscosities (Osemeahon et al., 2007; Trezza and Krochta, 2001).

At the beginning, the molecular weight increases with increase in viscosity until an optimum growth was observed. At the gel point, the resin may be characterized by molecular rearrangement and cross linking of molecules. This gives an account of the plateau regime observed in figure 2 (Osemeahon et al., 2007).

\section{Density}

In paint formulation, the density of the binder has profound influence on factors such as pigment dispersion, brushability of paint, flow, leveling and sagging (Osemeahon and Barminas, 2006a; Lowel, 1990). The effect of UF viscosity on the density of UF/UP copolymer is shown in figure 3 . The density increases with increase in UF viscosity until the gel point. This is then followed by a constant regime with further increase in viscosity. The increase in density with increase in UF viscosity is due to the increase in molecular weight while constant regime may be attributed to gelation (Sekaran et al.,
2001).

\section{Melting Point}

The melting point of a polymer is related to its molecular weight, degree of cross-linking and the level of rigidity of the polymer (Osemeahon and Barminas, 2006a). Figure 4 show the effect of UF viscosity on the melting point of UF/UP copolymer composite. This type of behavior agrees with the report of Ma et al. (2002) which was attributed to differences in molecular weight and cross link density of the copolymer network. At the beginning, the molecular weight increases with increase in UF viscosity until optimum growth was obtained. Molecular rearrangement and crosslink of resin molecules account for the equilibrium sate that followed this trend (Osemeahon et al., 2007).

\section{Moisture uptake}

The interaction of structural network of polymer resins with water is both of fundamental and technical interest (Osemeahon et al., 2007). Water uptake affects vital properties of the polymer such as, mechanical, thermal and structural properties (Hu et al., 2001; Nogueria et al., 2001). One of the major drawbacks of UF resins is their poor water resistance (Conner, 1996). In the paint making industry, the moisture uptake of the paint binder is very crucial because it is responsible for blistering and bromines of paint film (Barminas and Osemeahon, 2006b).

Figure 5 shows the effect of UF viscosity on the moisture uptake of UF/UP copolymer composite. It is observed that the moisture uptake decreases with increase in UF viscosity and becomes constant beyond the gel point. This result can be explained in terms of the differences in crosslink density at different UF viscosities (Noguria et al., 2001). As the viscosity of UF increases, the molecular weight and hence crosslink density also increases until the gel point is reached after which the crosslink density remained constant. The higher the crosslink density the lower the void spaces available for moisture accommodation (Osemeahon et al., 2007). This result suggests that a better water resistant UF/UP copolymer composite can be obtained at high UF viscosity. 


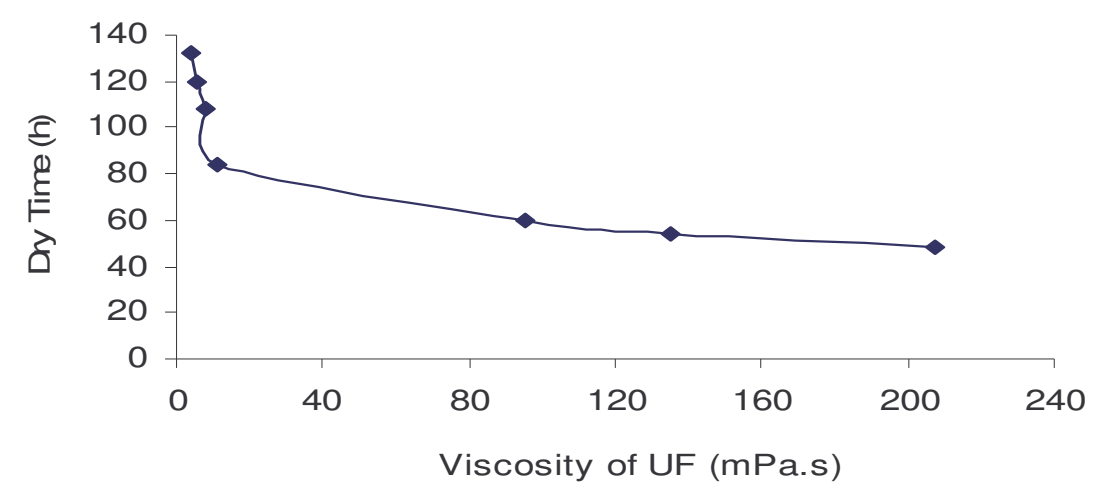

Figure 1: Effect of UF viscosity on the dry time of UF/UP copolymer.

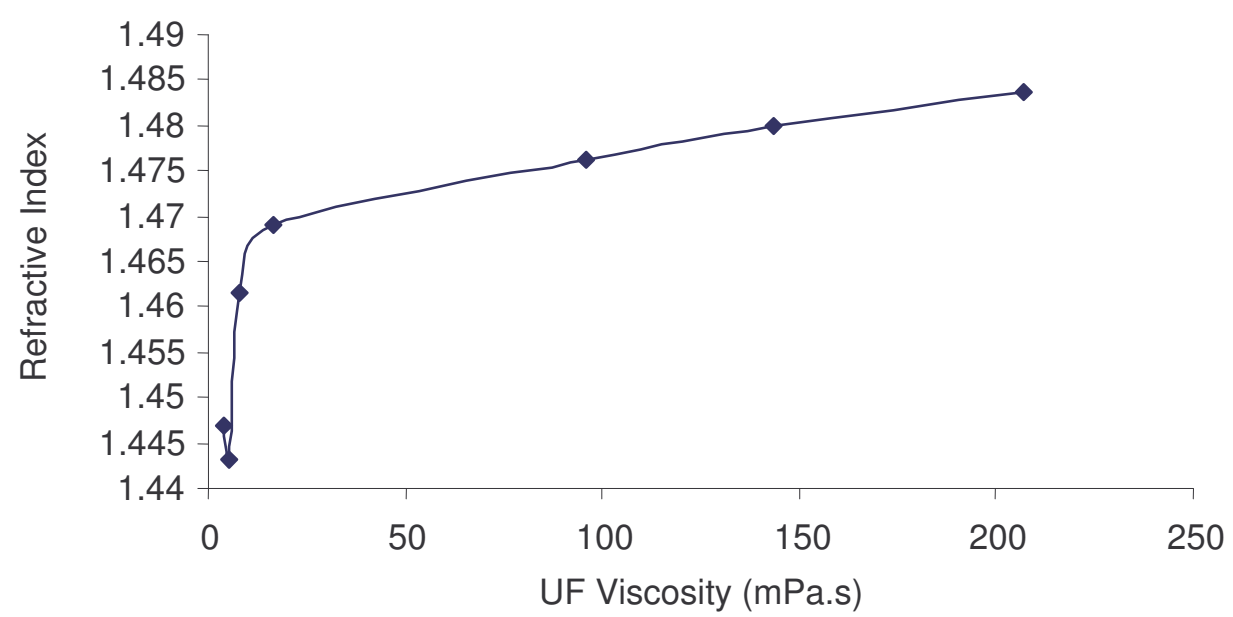

Figure 2: Effect of UF Viscosity on the Refractive Index of UF/UP Copolymer Composite.

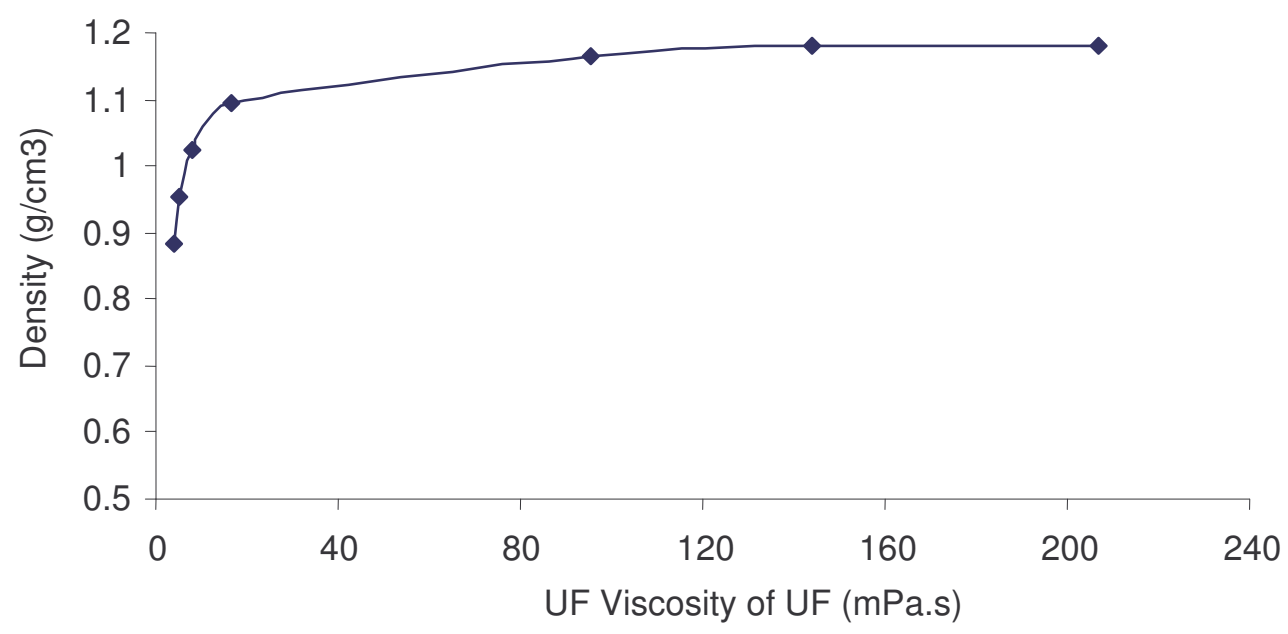

Figure 3: Effect of UF Viscosity on the Density of UF/UP Copolymer Composite. 


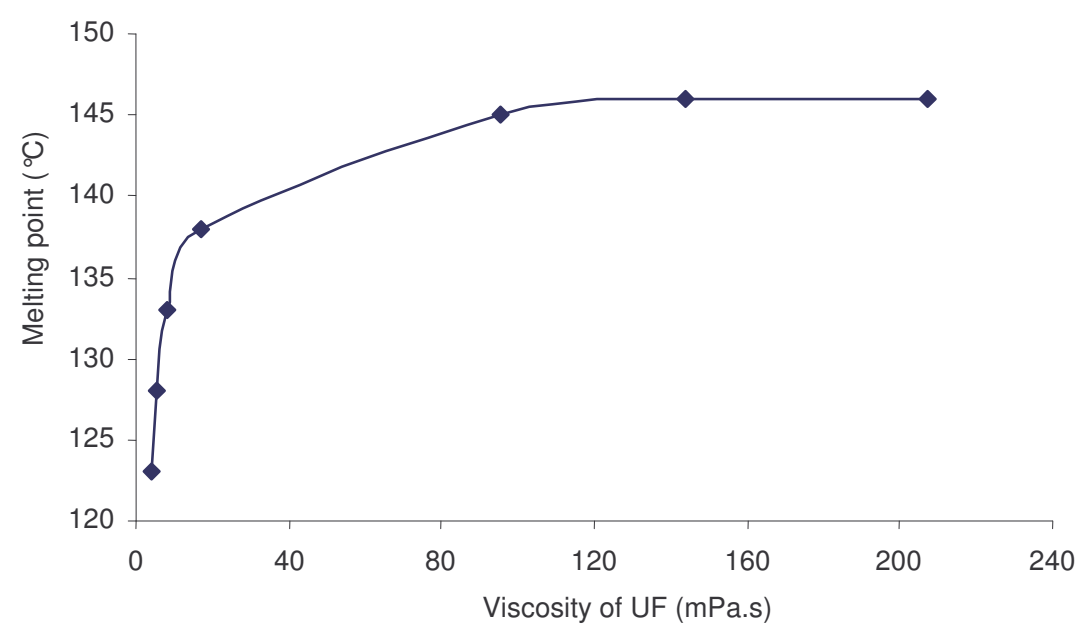

Figure 4: Effect of UF Viscosity on the Melting point of UF/UP Copolymer Composite.

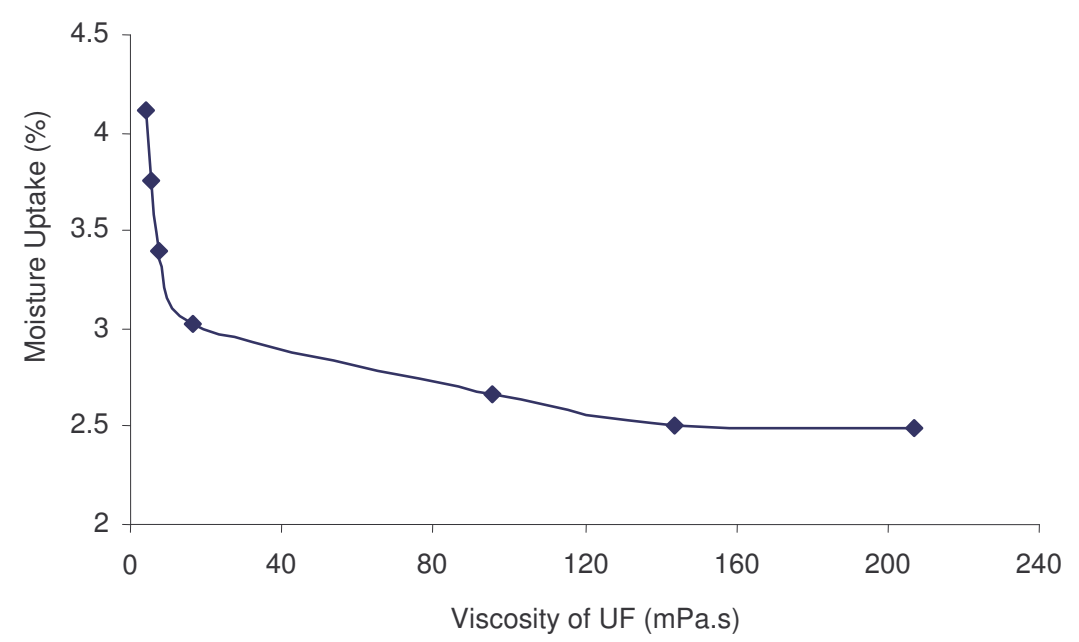

Figure 5: Effect of UF viscosity on the moisture uptake of UF/UP copolymer composite.

\section{Formaldehyde emission}

One of the major disadvantages of urea formaldehyde resin is the emission of the hazardous formaldehyde during cure (Kim, 2001). In the development of paint binder from urea formaldehyde resin, serious effort must be made to reduce formaldehyde levels to acceptable ones (Barminas and Osemeahon, 2006b).
Figure 6 shows the effect of UF viscosity on formaldehyde emission of UF/UP copolymer composite. It can be observed that the formaldehyde emission increases with increase in UF viscosity. This trend can be ascribed to two reasons; firstly, it may be due to increase in the rate of condensation reactions with increase in UF viscosity thereby increasing the rate of emission of 
formaldehyde in the process (Osemeahon et al., 2007; Nakason et al., 2001). Secondly, it may be due to increase in stress during resin cure with increase in UF viscosity. Reduction in stress during cure reduces emission (Osemeahon and Barminas, 2006b). Low UF viscosity gives rise to low molecular weight which favors molecular chain mobility and enhances flexibility of polymer network; flexibility reduces stress during cure and reduction of stress reduces emission (Osemeahon et al., 2007; Chian and Yi, 2001). Although an increased formaldehyde emission is recorded with increase in UF viscosity in this experiment, the maximum value $(0.042$ ppm) recorded is however still within acceptable limit (1.0 ppm) as stipulated by the environmental safety regulation (Kim, 2001). Therefore the effect of UF viscosity on formaldehyde emission of UF/UP copolymer is minor and can be tolerated.

\section{Tensile Test}

Elongation at break determines to what extend a material stretches before breaking and hence the ductility or flexibility of the material (Osemeahon et al., 2007). One of the shortcomings of UF resin is that it is too hard and brittle and hence poor resistance to crack propagation (Lowel, 1990). In the coating industry, a paint binder must be able to withstand stress emanating from variation in environmental factors. Therefore in developing paint binder from amino resin, tensile property such as elongation at break must be considered (Osemeahon and Barminas, 2006a).

The effect of UF viscosity on the tensile strength and elongation at break are shown in table 1 . It is observed that the tensile strength increases while the elongation at break decreases with increase in UF viscosity. This trend of result is attributed to the increase in molecular weight and hence crosslink density of the UF/UP copolymer with increase in UF viscosity (Ma et al., 2001). Differences in crystallinity or crystalline orientation of resin molecules with increase in UF viscosity may also be responsible for this result (Osemeahon et al., 2007). From these results the processing of UF/UP copolymer as a binder for emulsion paint formulation should be carried out at a viscosity below 10.84 $\mathrm{mPa}$.s. This will help to maintain the ductility of the material as the ductility is lost above this viscosity level (Ma et al., 2002; Osemeahon and Barminas, 2006b).

\section{Solubility in Water}

The development of amino resin for emulsion paint formulation requires an understanding of the solubility of the resin in water (Osemeahon and Barminas, 2006b). It is important both from the technical and processing point of view. This is more so because the solubility of urea formaldehyde resin decreases with increase in viscosity (Lowel, 1990; Osemeahon et al., 2007). Table 2 shows the effect of UF viscosity on the solubility of UF/UP copolymer resin in water. Below a viscosity of $10.82 \mathrm{mPa}$.s, the UF/UP copolymer is soluble in water and beyond this point the resin is insoluble in water. This result is attributed to differences in molecular weight and crosslink density (Lowel, 1990). Perharps, the viscosity of $10.82 \mathrm{mPa}$.s seems to represent the gel point of the copolymer resin. Thus processing of UF/UP copolymer for emulsion paint formulation could be suggested below this viscosity value.

Table 1: Effect of UF viscosity on the tensile properties (elongation at break and tensile strength) of UF/UP copolymer composite.

\begin{tabular}{|c|c|c|}
\hline Viscosity of UF (mPa.s) & Tensile Strength $\left(\mathrm{kg} / \mathrm{cm}^{3}\right)$ & Elongation at break $(\%)$ \\
\hline 3.91 & 0.158 & 135.32 \\
\hline 5.26 & 0.184 & 128.00 \\
\hline 7.9 & 0.210 & 124.52 \\
\hline 10.82 & $0 / .236$ & 120.09 \\
\hline 95.65 & 0.263 & 94.05 \\
\hline 134.78 & 0.272 & 92.31 \\
\hline 209.8 & 0.279 & 92.34 \\
\hline
\end{tabular}




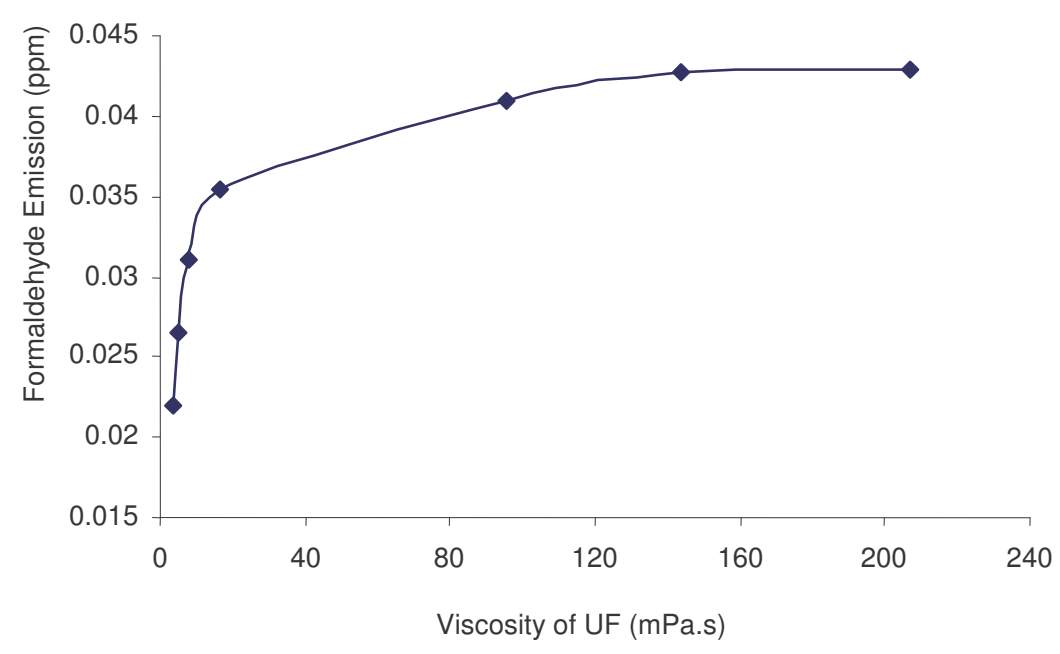

Figure 6: Effect of UF viscosity on the formaldehyde emission of UF/UP copolymer composite.

Table 2: Effect of UF viscosity on the solubility of UF/UP copolymer Resin in water.

\begin{tabular}{lc}
\hline Viscosity of UF (mPa.s) & Solubility in water \\
\hline 3.91 & Soluble \\
5.26 & Soluble \\
7.9 & Slightly soluble \\
10.82 & Insoluble \\
95.65 & Insoluble \\
134.74 & Insoluble \\
209.08 & Insoluble \\
\hline
\end{tabular}

\section{Conclusion}

The effect of UF viscosity on some physical properties of UF/UP copolymer composite has been examined. The result obtained shows that UF viscosity has a significant influence on the properties of UF/UP copolymer composite. At a viscosity below $10.82 \mathrm{mPa}$.s the copolymer film is ductile and soluble in water. Beyond this value, the copolymer resin is brittle and insoluble in water. Thus, processing the UF/UP copolymer resin for emulsion paint formulation could be suggested below this viscosity level. While the level of formaldehyde emission was found to increase with increase in UF viscosity that of moisture uptake on the other hand decrease with increase in UF viscosity. The result from this study will contribute immensely toward the optimization of the copolymerization reaction between UF and UP resins.

\section{REFERENCES}

Ali MM, Ooi T, Salmiah A, Ishaku S, Ishak ZAM. 2001. New polyester acrylate resins from palm oil for coating applications. J. Appl. Polym. Sci., 79: $2156-2163$.

AOAC. 2000. Official Method of Analysis International $\left(17^{\text {th }}\right.$ edn), Horwitz W (Ed). Gaithersburg Mongland, USA, Vol. 1, 41; 1-68.

Barminas JT, Osemeahon SA. 2007. Novel development of amino resins for paint formulation. 1. Effect of $\mathrm{pH}$ on a new synthetic route. European Journal of 
Scientific Research, 16: 160-173.

Barminas JT, Osemeahon SA 2006. Development of amino resins for paint formulation. 11. Effect of temperature on new synthetic route. , European Journal of Scientific Research. 14: 489-499.

Chain KS, Yi S. 2001. Synthesis and characterization of an isocyanurateoxazodidone polymer: Effect of stoichmetry. J. Polym. Sci., 82: 879-888.

Gan S, Tan B. 2001. FTIR studies of the curing reactions of palm oil alkydmelamine enamels. J. Appl. Polym. Sci., 80: $2309-2315$.

Gooch JW. 1997. Analytical and Deformulation of Polymeric Materials: Paints, Plastics, Adhesives and Ink. Kluwer Academic Publichers: New York, U. S. A; 119-120.

Johnson BM, Wilkes GL. 2001. Microporous membranes of polyoxymethylene from a melt-extrusion process: (1) effect of resin variables and extrusion conditions. $J$. Appl. Polym. Sci., 81: 2944- 2963.

Kim GM. 2001. Examination of selected synthesis parameters for wood adhesivetype urea-formaldehyde resins by CNMR spectroscopy. J. Appl. Polym. Sci., 80: $2800-2814$

Li W, Xie Z, Li Z. 2001. Synthesis, characterization of polyacrylate-g- carbon black and its application to soap-free waterborne coating. J. Appl. Polym. Sci., 81: 1100 - 1106.

Lowel HJ. 1990. Coatings. In: Encyclopedia of Polymer Science and Engineering, Kroschwitz JI, Mark HF, Bikales NM, Overberger CG, Menges G (eds). Vol. 3; p. 615.

Ma Z, Pang X, Zhang J, Ding H. 2002. Studies on compatilization of intumescent flame-retardant/PP compo-sites based on etched pp. J. Appl. Polym. Sci., 84: 12231232.

Mohammed AH, Bardam MB, Aglan AH. 2001. Waterborne methylamine adduct as corrosion inhibitor for surface coating. $J$. Appl. Polym. Sci., 80: 286 - 296.
Nakason C, Kaesman A, Homsin S, Kiatkanjornewong S. 2001. Rheological and curing behavior of reactive blending.1. Maleated natural rubbercassava starch. J. Appl. Polym. Sci., 81: 2803 - 2813.

Nogueira PC, Ramirez A, Torres MI, Abad J, Cano I, Lopez-bueno Barral L. 2001. Effect of water sorption on the structure and mechanical properties of an epoxy resin system. J. Appl. Polym. Sci., 80: 7180.

Osemeahon SA, Barminas JT. 2006a. Properties of a low viscosity ureaformaldehyde resin prepared through a new synthetic route. Bulletin of Pure and Applied Sciences, 25C: 67-76.

Osemeahon SA, Barminas JT. 2006b. A new synthetic route for amino resins for paint formulation: effect of sodium dihydrogen phosphate (NaHP) as catalyst. Bulletin of Pure and Applied Sciences, 25C: 111118.

Osemeahon SA, Barminas JT. 2007. Study of a composite from reaction blending of methylol urea with natural rubber. Afri. $J$. Biotechnol., 6(6): 810-817.

Osemeahon SA, Barminas JT, Aliyu BA Maina HM. 2007. Development of amino resins for emulsion paint formulation: effect of aldehydic group and degree of substitution. Afr. J. Biotechnol, 6(22): 2532-2540

Sekaran G, Thamizharasi S, Ramasami T. 2001. Phsiochemical-modified polyphenol impregnate. J. Appl. Polym. Sci., 81: 1567 - 1571 .

Trezza AT, Krochta JM. 2001. Specular reflection, gloss, roughness and surface heterogeneity of biopolymer coatings $J$. Appl. Polym. Sci., 79: 2221 - 2229.

Trumbo DI, Mole EB, Travino SA, Denbrink VM. 2001. Coplymerication behavior of 3 -isopropyl- $\alpha$ - $\alpha$-dimethyl benzylamine and a preliminary evaluation of the copolymer in thermosetting coatings. $J$. Appl. Polym. Sci., 82: 1030-1039. 